\title{
Management's Commitment, Education and Ethics on Organisational Entrepreneurship: The Case of South African Non-Profit Organisations
}

\author{
*Rukudzo Pamacheche, Richard Chinomona, Tinashe Chuchu \\ University of the Witwatersrand, Johannesburg, South Africa \\ *Rukudzo.pamacheche@gmail.com, Richard.chinomona@wits.ac.za, tinashe.chuchu@wits.ac.za
}

\begin{abstract}
The objectives of the study were to explore the management characteristics that are related to organisational entrepreneurship in not-for-profit organisations (NPOs) in Gauteng, South Africa as well as the relationship between organisational entrepreneurship and the organisational performance. The methodology involved a quantitative approach of collecting and analysing research data. A field study was conducted in Johannesburg, South Africa whereby research data were collected from 257 NPO managers from voluntary organizations. Using the SPSS 22 and the AMOS 22 software program, Structural Equation Modeling (SEM) was performed to analyze the research data. The study noted implications for NPO management teams, including the renovation of business model structures to incorporate continuous learning and constructive risk-taking in order to take advantage of the performance benefits derived from organisational entrepreneurship. The study also recommends further research into potential citizenship bodies for NPO management teams to foster commitment to their occupation in the non-profit sector. The research makes a significant contribution by providing a framework in which management's commitment to NPOs can be measured and analysed.
\end{abstract}

Keywords: Management, Education, Non-Profit Organisations

\section{Introduction}

Entrepreneurship as a field of study has attracted a great deal of attention over the years (Amezcua, Grimes, Bradley, \& Wiklund, 2013 and Miller, Steier\& Breton-Miller, 2016). The study is of importance within a local context considering that entrepreneurship is key to alleviating poverty as highlighted by the work of (RiveraSantos, Holt, Littlewood \& Kolk, 2015).In today's aggressive competitive environment, organisations are constantly evolving and engage in entrepreneurial initiatives (Kantur, 2016). Furthermore, Kantur (2016) posits that Inflexibility, risk aversion, and fatigue accentuated by mechanistic organizations impede the development of entrepreneurial activities and therefore would not be regarded as a desirable approach to organisational development. Entrepreneurship can be applied to organisations that are driven by a profit motive, which can be identified as for-profit organisations, and those motivated to address social needs, which can be identified as non-profit organisations (NPOs) (Weerawardena \& Sullivan-mort, 2001).Whether an organisation's core objective is to make financial profit or serve social needs, the key ingredient for operating in a market is the ability to offer value to consumers (Kotler \& Keller, 2012). Both NPOs and forprofit enterprises engage in exchanges with other entities so as to benefit themselves and the other entities. This research is interested in exploring how management characteristics in NPOs would relate to the extent of innovativeness of NPOs and furthermore, how this relates to the performance of the NPO. Organisations tend to attempt to prevent unethical behaviour in organisations through ethics management interventions as this is believed to keep organisations in compliance with rules and regulations (Van Vuuren \& Crous, 2005).

Context of the Study: The present study is grounded in the context of NPOs in the Gauteng province, South Africa focusing on management characteristics that may be impacting how NPOs provide value to consumers who depend on them for various needs, such as food, shelter, education and care, among other needs. There are for-profit organizations that provide similar services (Chalmers \& Balan-Vnuk, 2012), but interest has been generated in NPOs due to NPOs being considerable contributors of needed services to vulnerable consumers. A non-profit organisation (NPO) is essentially an organisation that operates to provide a particular value offering without the intention to profit (Grobman, 2008). In cases where the organisation reports a surplus over its expenses, surplus funds are not distributed to shareholders or owners, but are re- 
invested into the organisation to help satisfy the goals of the organisation (Harris, 2012). NPOs have been generally known to provide services that governments consider important but for-profit organisations deem to be either not-profitable, and therefore do not provide them and offer these services at prices that cannot be afforded by everyone who needs them (Austin, Stevenson \&Wei-Skillern, 2006). The value that NPOs create is termed social value because it appeals to the needs of beneficiaries, or those who need the essential services (Austin et al., 2006; Yujuico, 2008) but are not able to access them from for-profit organisations. Examples of NPOs include charitable organisations, environmental, animal and other foundations, public associations, trade unions and other humanitarian associations (Crutchfield \& Grant, 2012).

Purpose of the Study: The purpose of the current study is to determine the relationships between certain management characteristics, organisational entrepreneurship and organisational performance of NPOs. Through understanding how the capabilities influence operational performance, contributors and management teams would be better able to determine how to improve the organisational performance of the NPO (Weerawardena \& Sullivan-mort, 2008). Management characteristics such as professional commitment, professional education, professional ethics and contribution towards organisational entrepreneurship have an impact on organisational entrepreneurship (Wood, Bhuian \& Kieker, 2000). The focus in this study is on management's commitment to their occupation in the non-profit sector, management's continuous education, and management's ethics as internal contributors to the organisation's entrepreneurship. The remainder of this paper provides background on the literature adopted for the study, the research conceptual model and research methodology. This is then followed by the data analysis section, results as well as some important implications for both practitioners and academicians. The present paper ends with a conclusion, recommendations and possible suggestions for future research.

\section{Literature Review}

Creswell (2013) posits that literature serves the purposes of sharing findings of other studies related to the study at hand, relating the study to a larger ongoing conversation in literature as well as fillings gaps and extending prior studies. The following section explores the literature adopted for the present study.

Theory of Innovative Enterprise: The function of enterprises in the economy is to convert resources into valuable goods and services that can be consumed (Drucker, 1998). An economic theory of this nature on enterprises posits that three major activities contribute to the enterprise's success, namely the enterprise's strategy, its organisation and its finances (Schuster \& Holtbrügge, 2014). Through its strategy, the enterprise develops its human and physical capabilities by allocating resources that will enable the enterprise to better create value for its consumers (Naidoo, 2011). Concurrently, the theory presents a perspective of entrepreneurship that highlights an organisation's ability to allocate and use its available resources (Drucker, 1998; Austin et al., 2006). This is considered as a central aspect of the organisation's ability to continuously create new value for its clients.

Organisational Learning: Argote and Miron-Spektor (2011) refer to organisational learning as a series of processes in an enduring cycle where the experience is converted to knowledge. Outside the organisation, the learning happens within an environmental context affected by consumers or political, climatic, competitive or legal factors. Organisational learning in organisational theory recognises that employees in organisations need to continuously acquiring new knowledge and skills beyond the context or present scope of the organisation (Drejer, 2000). Two essential elements that remain persistent in the running of organisations are their innovation and marketing (Drucker, 1998), which continuously require employees to effect positive changes by learning and developing new ways of improving the value being offered by their organisation.

Market orientation: Market orientation is a business philosophy based on the notion that the needs of the consumer determine the goods and services that an organisation provides (Wood et al., 2000; Kumar, Jones, Venkatesan \& Leone, 2011), and any changes in the goods and services provided by the organisation are motivated primarily by the consumers' changes in demands (Hult, 2011). This differs from a product orientation, which considers the product or service to be more important than consumer needs, and hence expects consumers to adapt their needs to the products (Kotler \& Keller, 2012). 
Organisational entrepreneurship: Organisational entrepreneurship can be described as the eagerness of the organisation to be creative, flexible and be able to take calculated risks (Wood et al., 2000), as effected by its members. Van Vuuren \& Crous (2005) suggested that organisations that harm their reputations through scandals relating to unethical behaviour may take a long period of time to recover and regain their reputations. Within a local context importance of entrepreneurship is highlighted by (Chimucheka, 2015; Maziriri \& Chinomona, 2016) who posit that small businesses are responsible for employment creation, poverty reduction and reducing levels of inequality.

Management's Commitment to their Occupation: It has been established that employees remain committed to their work because of a psychological bond that keeps them attached to their profession (Cho \& Huang, 2012). This is seen in professions such as Information Technology (IT) and Accounting, where employees become members of a society with other professionals, to occasionally engage in professionrelated issues and for social purposes (Fu, Bolander \& Jones, 2009). When it comes to managers in NPOs, commitment is important to the organisation because it shows confidence in managers and their intention to continue providing value to consumers who need to benefit from NPOs (Huarng \& Yu, 2011). Furthermore, commitment facilitates flexibility in the organisation and helps to construct risk-taking abilities in managers (Fairlie \& Holleran, 2012). It indicates intention for the organisation to remain operating in the market, and it allows for potential of improvement of services through innovative processes (Wood et al., 2000).

Management's Continuous Education: Markets are continuously evolving therefore imperative for managers to remain relevant with the changes in order to make good and progressive decisions for their firms (Kotler \& Keller, 2012). Management's continuous education refers to managers' ability to continue to develop their professional skills and knowledge in various forms. This relates well to the concept of a learning organisation, in which members develop the perspective of acquiring new knowledge relevant to their industry and implement informed decisions that benefit the organisation (Chiva, Grandío \& Alegre, 2010). Senior managers believe in continuously developing their skills and knowledge to ensure that the organisation is aware of methods of providing higher quality services for their clients (Sessa, London, Pingor, Gullu \& Patel, 2011). This has been seen in IT professionals (Cho \& Huang, 2012) actuaries and academics who, as part of their associations, attend conferences and workshops to remain current about their professional fields.

Management's Ethics: Management ethics refer to the codes and practices that managers adhere to that ensure that they put the interests of the organisation before their own (Wood et al., 2000). Ethics bring all members of the organisation under a common vision for the organisation (Garcia-Morales, Llorens-Montes \& Verdú-Jover, 2006). The presence of ethics in the organisations promotes managers to make constructive decisions that uplift the organisation rather than disadvantage it (Kao, Kao \& Kao, 2005). The King Committee on Corporate Governance (2009) suggests that managers with ethics take calculated risks that benefit the organisation as they are committed to ensuring that the organisation continues to operate well into the future, continuing to provide quality services to their clients (Matei, Bolcas, Badea \& Carstea, 2010).

Organisational Performance: Common impressions of organisational performance refer to the profitability of the organisation (Albrecht, Stice \& Stice, 2011). How an organisation performs depends on how well it fulfils its objectives and mandate for existing in the market (Kotler \& Keller, 2012). In the case of the NPOs, is the ability to serve its community with valuable offerings that improve their livelihood. 
Figure 1: Research Conceptual Model

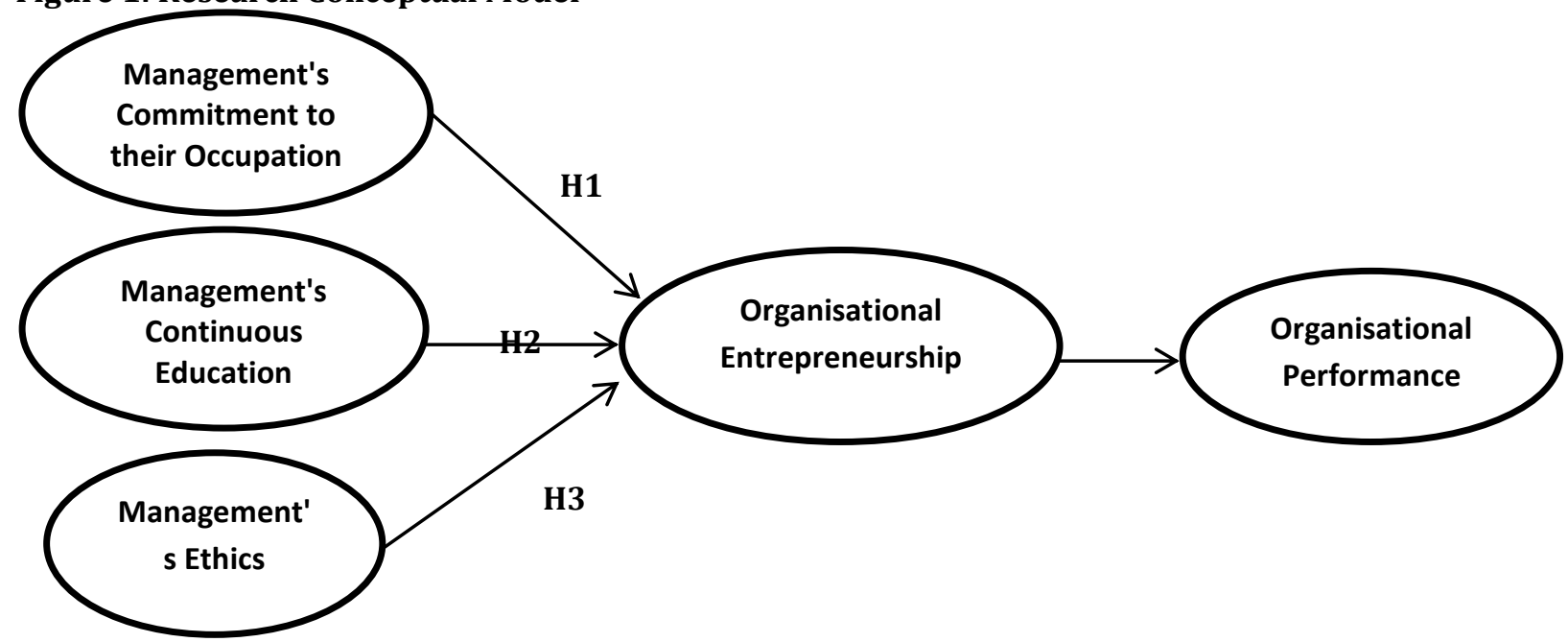

Research Conceptual Model: The proposed conceptual model below in figure1 consists of three predictor variables: Management's Commitment to their Occupation (MCO), Management's Continuous Education (MCE), and Management's Ethics (ME) that influence the mediator Organisational Entrepreneurship (OE) which ultimately influences Organisational Performance (OP).

Management's commitment to occupation and organisational entrepreneurship: In NPOs' market orientation, management's commitment to the organisation positively and directly influences the organisational entrepreneurship (Wood, et al., 2000). Taking a South African perspective Bargraim (2003) suggests that more committed managers dedicate more time and effort to understanding and experiencing their industry's risks and opportunities, and contributing to making the organisation flexible to respond to changes that affect the organisation (Chalmers \& Balan-Vnuk, 2012). The level of managements' commitment to their occupation in the voluntary organisation may demonstrate the managers' willingness to remain in this non-profit industry, even when offered a similar position in another industry (Wood et al., 2000). From this literature, the first hypothesis was postulated.

H1: Management's commitment has a positive relation with on organisational entrepreneurship

Management's continuous education affects organisational entrepreneurship: Managers can generate intelligence on which to base their decisions in response to the changes in the industry and ways of improving their offerings. Making informed decisions helps to minimise the risks of failure that may be associated with adopting certain technologies or reacting to changes in the market environment. It is therefore assumed that managers' continuous learning has a positive influence to organisational entrepreneurship. Learning experiences that aid creativity are important for bridging gaps in knowledge, which is why strong emphasis is placed on individuals engaging continuously in learning and skills improvement (Chiva et al., 2010). From this, the second hypothesis was postulated. According to Draper, Clark and Rogers (2016) healthcare organisations encounter challenges in providing care in the continuously increasing difficult environment and are encouraging staff to take up ongoing professional education courses as it is critical for staff to maintain and develop their knowledge and skills.

H2: Management's continuous education has a positive relation with organisational entrepreneurship.

Managers' ethics influence on organisational entrepreneurship: Theory surrounding market orientation considers managerial ethics to be important for facilitating principled risk-taking by senior managers (Wood et al., 2000). This element of risk is inherent in entrepreneurial thinking (Mort, Weerawardena \& Carnegie, 2003). Since senior managers are responsible for making decisions that affect the organisation, their ethical standards affect how well they perceive risk and the effect that risk would have on the organisation. Management's ethics are therefore have a positively influence on the internally generated entrepreneurship of an organisation. This allowed the third hypothesis to be postulated.

H3: Management's ethics have a relation with organisational entrepreneurship. 
Organisational Entrepreneurship and Performance: The purpose of managers contributing to the organisational entrepreneurship is to facilitate innovation that will make the organisation more successful in its activities of providing valuable offerings to certain consumer segments. While the connection between entrepreneurial orientation and organisational performance widely accepted in literature, recent research started to refocus on the measurement of entrepreneurial orientation construct (Kantur, 2016). The ability of the organisation to learn and adapt to changes and development in the market impact their ability to provide better services through efficient use of scarce resources, to reach more consumers and to attract volunteers. Organisational entrepreneurship is therefore assumed to have a positive relation to organisational performance. The fourth hypothesis was then postulated as follows:

H4: Organisational entrepreneurship has a relation with organisational performance.

\section{Methodology}

Research Design: The study adopted the positivist paradigm, a philosophy that is of the view that knowledge stems from human experience (Collins, 2010). A quantitative research approach was used for this study. Probability sampling was adopted for the present research and was deemed appropriate as it assumes every respondent in the population had an equal chance of being included in the research, and thus reduced bias toward certain respondents (Galpin, 2013).A list of the members of this population was available in the directory of Non-profit Organisations, which was accessed on the website of the South African Department of Social Development (DSD) (Department of Social Development, 2014). Additional lists were also accessed from the Wits Citizenship and Community Outreach (WCCO), a facilitator of volunteer-led work at the University of the Witwatersrand. As far as basic parameters were concerned the study was limited only to NPOs based in the Gauteng province and this could have marginalised the findings of the study.

Measurement Instruments: The research constructs were adapted from prior studies of the same field of study. Sufficient adaptations were made to the research constructs so as to take in into consideration the current study's context and purpose. To collect data a likert scale questionnaire was utilised.

Survey Design: Fagarasanu \& Kumar (2002) posit that the theoretical constructs in any study that are measured are the determining factors for the choice of measurement methodology. For purposes of the present research, senior managers were asked to complete a self-administered hard copy questionnaire with one section on background information, and the rest of the sections relating to the constructs under study. Sections B to F measured each of the constructs on five-point Likert scales, with questions adapted from various relevant scales used in previous research. The decision to use five-point Likert scale rather than seven-point Likert scale was based on knowledge that mean scores for either scales may not differ significantly and are readily transferrable by rescaling (Dawes, 2008). The questionnaire is available in Appendix A of this report.

\section{Results of the Study}

Respondent Profile: The profile of the participants is presented in Table 1 on the following page. The sample presents five organisational types which are as follows: health and disability (20.6\%), other care (29.2\%) and advocacy $(16.0 \%)$ of the total sample. Furthermore it can also be observed that education and other categories represented (20.2\%) and (14.0\%) respectively. Members supported by NPO ranged from groups of 1-20 members and 41-60 members. Years of experience in NPOs and in current NPO ranged from 1-5 years and 20+ years. Various educational backgrounds, job titles and age groups are represented as well as gender sampled in the study. 
Table 1: Sample Demographic Profile

\begin{tabular}{|c|c|c|c|c|}
\hline Research construct & Category & Frequency & $\begin{array}{l}\text { Percent } \\
(\%)\end{array}$ & $\begin{array}{l}\text { Cumulative } \\
\text { Percent (\%) }\end{array}$ \\
\hline & Health and Disability care & 53 & 20.6 & 20.6 \\
\hline & Other Care & 75 & 29.2 & 49.8 \\
\hline \multirow[t]{5}{*}{ Organisation type } & Advocacy & 41 & 16.0 & 65.8 \\
\hline & Education & 52 & 20.2 & 86.0 \\
\hline & Other & 36 & 14.0 & 100.0 \\
\hline & Total & 257 & 100.0 & \\
\hline & $1-20$ & 97 & 37.7 & 37.7 \\
\hline Members supported by & $21-40$ & 128 & 49.8 & 87.5 \\
\hline \multirow[t]{4}{*}{ NPO } & $41-60$ & 32 & 12.5 & 100.0 \\
\hline & Total & 257 & 100.0 & \\
\hline & $1-5$ & 63 & 24.5 & 24.5 \\
\hline & $6-10$ & 64 & 24.9 & 49.4 \\
\hline Years' experience in & $11-15$ & 72 & 28.0 & 77.4 \\
\hline \multirow[t]{5}{*}{ NPOs } & $16-20$ & 47 & 18.3 & 95.7 \\
\hline & $20+$ & 11 & 4.3 & 100.0 \\
\hline & Total & 257 & 100.0 & \\
\hline & $1-5$ & 99 & 38.5 & 38.5 \\
\hline & $6-10$ & 73 & 28.4 & 66.9 \\
\hline \multirow[t]{4}{*}{ Years in current NPO } & $11-15$ & 51 & 19.8 & 86.8 \\
\hline & $16-20$ & 23 & 8.9 & 95.7 \\
\hline & $20+$ & 11 & 4.3 & 100.0 \\
\hline & Total & 257 & 100.0 & \\
\hline Educational & Social welfare & 59 & 23.0 & 23.0 \\
\hline \multirow[t]{5}{*}{ background } & Health & 63 & 24.5 & 47.5 \\
\hline & Business / Commerce & 68 & 26.5 & 73.9 \\
\hline & Public administration & 37 & 14.4 & 88.3 \\
\hline & Other & 30 & 11.7 & 100.0 \\
\hline & Total & 257 & 100.0 & \\
\hline \multirow[t]{6}{*}{ Job title } & Executive / Board member & 64 & 24.9 & 24.9 \\
\hline & Senior manager & & & \\
\hline & Operational manager & & & \\
\hline & Administrative & & & \\
\hline & Other & & & \\
\hline & Total & 257 & 100.0 & \\
\hline \multirow[t]{6}{*}{ Age group } & $20-30$ & 28 & 10.9 & 10.9 \\
\hline & $31-40$ & 42 & 16.3 & 27.2 \\
\hline & $41-50$ & 66 & 25.7 & 52.9 \\
\hline & $51-60$ & 88 & 34.2 & 87.2 \\
\hline & over 60 & 33 & 12.8 & 100.0 \\
\hline & Total & 257 & 100.0 & \\
\hline \multirow[t]{3}{*}{ Gender } & Male & 53 & 20.6 & 20.6 \\
\hline & Female & 204 & 79.4 & 100.0 \\
\hline & Total & 257 & 100.0 & \\
\hline
\end{tabular}

Model Fit: Table 2 below illustrates the model fit indices of the present study. All the model fit indices met the recommended thresholds as discussed in greater detail in the section that follows.

Table 2: Model Fit

\begin{tabular}{|c|c|c|c|c|c|c|}
\hline Model fit criteria & Chi-square ( $\chi 2 / D F)$ & CFI & IFI & NFI & TLI & RMSEA \\
\hline Indicator value & 2.361 & 0.93 & 0.93 & 0.90 & 0.91 & 0.07 \\
\hline
\end{tabular}


Scale Accuracy Analysis: The scale construct correlations are presented in table 2. Results of scale reliability are presented in table 2 whereby Cronbach's alpha coefficients were above 0.75 exceeding the 0.7 recommended by (Venter, Chuchu \& Pattison, 2016) while the composite reliability values ranged from 0.701 to 877. Furthermore it was observed that most of the AVE values were above 0.59 . The measurement model produced a ratio of chi-squared value over degree-of-freedom of 2.361 which is acceptable as it fall below the 3 recommended by (Ullman \& Bentler, 2003). The other model fit indices include the CFI, IFI, NFI and the TLI were $0.93,0.93,0.90$, and 0.91 respectively. All these model fit measures were above recommended threshold of 0.8 by (Chinomona, Lin, Wang, \& Cheng 2010). The RMSEA was 0.07 which fell below the recommended threshold of 0.08 by (Hooper, Coughlan \& Mullen, 2008).

Path Modelling \& Hypotheses Testing: From Table 3, the findings reveal that all four hypotheses are supported. H1 and H2: Management's commitment to their occupation and continuous education directly and positively influences organizational entrepreneurship. The outcome of $\mathrm{H} 1$ is similar to (Rashid, Sambasivan \& Johari, 2003) who established that commitment directly influences entrepreneurship positively. Both relationships imply that the more an organization is committed to its obligations and the drive to learn more the more a culture of entrepreneurship is encouraged within that organization. H3: Management's ethics also have a positive and direct impact on organizational entrepreneurship. This relationship lastly implies that organizations that are ethical encourage their employees to be entrepreneurial. Lastly, H5: Organizational Entrepreneurship leads to organizational performance. This implies that organizations that are entrepreneurial tend to become more successful. Table 4 presents the results of the structural equation modelling followed by discussion thereof.

Table 3: Accuracy Analysis Statistics

\begin{tabular}{|c|c|c|c|c|c|c|c|c|c|c|}
\hline \multirow[t]{2}{*}{ Research Construct } & & \multicolumn{4}{|c|}{ Descriptive Statistics } & \multicolumn{2}{|c|}{ Cronbach's Test } & \multirow{2}{*}{$\begin{array}{l}\text { C.R. } \\
\text { Value }\end{array}$} & \multirow{2}{*}{$\begin{array}{l}\text { AVE } \\
\text { Value }\end{array}$} & \multirow{2}{*}{$\begin{array}{l}\text { Factor } \\
\text { Loading }\end{array}$} \\
\hline & & \multicolumn{2}{|c|}{ Mean Value } & \multicolumn{2}{|c|}{$\begin{array}{l}\text { Standard } \\
\text { Deviation }\end{array}$} & Item-total & $\alpha$ value & & & \\
\hline \multirow{3}{*}{$\begin{array}{l}\text { Management's } \\
\text { commitment } \\
\text { occupation }\end{array}$} & $\mathrm{MgCm} 2$ & 4.21 & & 0.64 & & 0.462 & & & & 0.702 \\
\hline & $\mathrm{MgCm} 4$ & 4.13 & 4.13 & 0.72 & 0.69 & 0.486 & 0.747 & 0.701 & 0.439 & 0.644 \\
\hline & $\mathrm{MgCm}$ 5 & 4.05 & & 0.72 & & 0.417 & & & & 0.639 \\
\hline \multirow{5}{*}{$\begin{array}{l}\text { Management's continuous } \\
\text { education }\end{array}$} & MgEdu1 & 4.13 & & 0.80 & & 0.473 & & & & 0.721 \\
\hline & MgEdu2 & 3.98 & & 0.70 & & 0.548 & & & & 0.655 \\
\hline & MgEdu3 & 4.00 & 4.05 & 0.63 & 0.65 & 0.565 & 0.831 & 0.830 & 0.495 & 0.621 \\
\hline & MgEdu4 & 4.10 & & 0.56 & & 0.618 & & & & 0.735 \\
\hline & MgEdu5 & 4.04 & & 0.56 & & 0.567 & & & & 0.775 \\
\hline \multirow[t]{5}{*}{ Management's ethics } & MgEth1 & 4.30 & & 0.71 & & 0.509 & & & & 0.743 \\
\hline & MgEth1 & 4.10 & & 0.67 & & 0.548 & & & & 0.745 \\
\hline & MgEth3 & 4.20 & 4.23 & 0.65 & 0.69 & 0.564 & 0.872 & 0.877 & 0.589 & 0.737 \\
\hline & MgEth4 & 4.13 & & 0.67 & & 0.600 & & & & 0.776 \\
\hline & MgEth5 & 4.41 & & 0.73 & & 0.696 & & & & 0.832 \\
\hline \multirow[t]{5}{*}{$\begin{array}{l}\text { Organizational } \\
\text { entrepreneurship }\end{array}$} & $\begin{array}{l}\text { OrEntr1 } \\
\text { OrEntr2 }\end{array}$ & $\begin{array}{l}3.86 \\
4.03\end{array}$ & & $\begin{array}{l}0.64 \\
0.78\end{array}$ & & $\begin{array}{l}0.494 \\
0.622\end{array}$ & & & & $\begin{array}{l}0.578 \\
0.684\end{array}$ \\
\hline & OrEntr3 & 4.14 & 4.05 & 0.87 & 0.81 & 0.550 & 0.864 & 0.859 & 0.506 & 0.745 \\
\hline & OrEntr4 & 4.09 & & 0.89 & 5 & 0.599 & & & & 0.747 \\
\hline & OrEntr5 & 3.84 & & 0.79 & & 0.642 & & & & 0.733 \\
\hline & OrEntr6 & 4.33 & & 0.92 & & 0.466 & & & & 0.764 \\
\hline \multirow{3}{*}{$\begin{array}{l}\text { Organization's } \\
\text { performance }\end{array}$} & OrPerf1 & 4.40 & & 0.76 & & 0.602 & & & & 0.816 \\
\hline & OrPerf3 & 4.01 & 4.15 & 0.64 & 0.78 & 0.512 & 0.847 & 0.874 & 0.583 & 0.785 \\
\hline & OrPerf4 & 3.95 & & 0.84 & & 0.564 & & & & 0.678 \\
\hline
\end{tabular}


Note: Management's commitment to occupation (MgCmt), Management's continuous education (MgEdu), Management's ethics (MgEth), Organizational entrepreneurship (OrEntr), Organization's performance (OrPerf). C.R.: composite reliability; AVE: average variance reliability.

Structural model fits: $\chi 2 / d f=; C F I=0.93 ; T L I=0.91 ; I F I=0.93 ; N F I=0.90 ; R M S E A=0.07$ a significance level $p$ $<0.01$

Table 4: Results of Structural Equation Model Analysis

\begin{tabular}{|c|c|c|}
\hline Hypothesis & Description of Relationship & Outcome \\
\hline $1(\mathrm{p}<0.1)$ & $\begin{array}{l}\text { Management's commitment to their occupation has a } \\
\text { positive relation with organizational entrepreneurship. }\end{array}$ & $\begin{array}{l}\text { Not Supported } \\
\text { (0.382) Path Coefficient }\end{array}$ \\
\hline $\mathrm{H} 2(\mathrm{p}<0.01)$ & $\begin{array}{l}\text { Management's continuous education has a positive } \\
\text { relation with on organizational entrepreneurship. }\end{array}$ & $\begin{array}{l}\text { Supported and significant } \\
\text { (0.607) Path Coefficient }\end{array}$ \\
\hline $\mathrm{H} 3(\mathrm{p}<0.01)$ & $\begin{array}{l}\text { Management's ethics have a positive relation with } \\
\text { organizational entrepreneurship. }\end{array}$ & Supported and significant \\
\hline $\mathrm{H} 4(\mathrm{p}<0.01)$ & $\begin{array}{l}\text { Organizational entrepreneurship has a positive relation } \\
\text { with organizational performance. }\end{array}$ & Supported and significant \\
\hline
\end{tabular}

Structural model fits: $\chi^{2} / d f=; C F I=0.93 ; T L I=0.91 ; I F I=0.93 ; N F I=0.90 ; R M S E A=0.07^{a}$ significance level $p<0.01$

\section{Conclusion}

Management continuous education has proven to be a management competency that allows management teams to contribute to their NPOs' entrepreneurship capabilities. The importance lies in encouraging continuous learning of employees to enable them to remain relevant in terms of important information about technologies and their industries that affects their organisations. With ever-changing needs of consumers who are dependent on NPOs, innovative learning can only be encouraged more as discontinuing or reducing momentum to learn could result in reversed in providing innovated social value. Due to theoretical differences in concepts of profession and occupation, commitment of NPO managers to their occupation in the non-profit sector proved to be less influential than continuous education. This shows a lack of the competency to influence internally the NPO's entrepreneurship. Capabilities of NPO managers could be enhanced through the creation of knowledge sharing bodies, which can be achieved through commitment of managers to such bodies to benefit from pooled knowledge hubs that are necessary for driving innovation. The current study views government support as vital for the continuity, competitiveness and efficiency of NPOs as supported by Chawarika (2016) who states that the government is considered as an active player in influencing the competitiveness of firms. The overall resolve of managers in the sample of NPOs to "do the right thing" and continually create benefit for their organisations does little to make a significant impact on the organisation's entrepreneurship. The restraint element, accompanied by management teams being risk averse, may be responsible for limiting managers' contributions to entrepreneurship that could benefit their organisations. This highlights the importance of instilling principles of constructive risk-taking educational efforts to allow managers to learn about benefits of investing and managing risk in order to be sustainable.

Implications of the Study: The present study offers implications for managers and academicians with regards to management and entrepreneurship of NPOs in South Africa. Based on the results of the current study organizational entrepreneurship and organizational performance $(\mathrm{H} 4)$ is seen to be the strongest relationship implying that for managers to have successful NPOs there are required to provide incentives for their employees to have entrepreneurial mindsets. A key finding of the present study was that managers of NPO are now encouraged to utilize organizational resources supporting entrepreneurship within their organizations. This finding is supported by Kong (2007) who found that it has increasing become imperative for more managers to operate more resourcefully so as to increase organisational effectiveness. However it is 
also observed based on the results that management's commitment to their occupations and organizational entrepreneurship is a relationship that is not supported. This implies that the commitment from managers of NPOs does necessarily lead to employee entrepreneurship. Other major implications for managers in NPOs are highlighted in this research. Firstly, management groups in NPOs that are interested in increasing their organisational entrepreneurship may consider creating or renovating in their business models structures to make provision for continuous education of their management teams in order to help managers to improve their contributions, and ultimately improve the performance of the organisation. The strong influence of continuous education on entrepreneurship for the organisation may encourage managers to invest in learning and knowledge sharing initiatives, such as workshops, seminars and conferences to contribute to their organisations' entrepreneurship.

Given the importance of management commitment to operational consistency and continuation, managers in NPOs should be encouraged to form or join collective bodies or societies that can help to moderate, maintain and encourage citizenship to the non-profit sector and knowledge generation relevant to the NPOs. This finding is reflected in a past study by (Balser \& McClusky, 2005) who established that committed managers of NPOs are able to successfully conduct their practises so as to contribute to organisational effectiveness. Another managerial implication concerns building up management teams in NPOs to engage in constructive risk-taking with the organisation's resources. Being risk averse may come from fear of failure of fundraising projects or due to uncertainty, is a hindering element of entrepreneurship. The question may arise as to why NPOs should be entrepreneurial at all, to which NPO management teams can expect that, in a world of everchanging circumstances, for-profit and not-for-profit organisations operate in a market-structured economy which runs on competitiveness for scarce resources.

Recommendations for Further Research: Recommendations for further research are directed at both practitioners and academicians, and are based on contributions to knowledge made during the research as well as ways of addressing limitations of the research. Given the positive impacts of management characteristics on entrepreneurship within NPOs observed in the current study, researchers may also extend studies to include non-managerial members of the organisation, because the capabilities of all members of an organisation help to implement the organisation's mandate. The intention would be for researchers and practitioners to consider investigating the likelihood of business model renovations that factor in the competencies being adopted by both volunteer and non-volunteer intensive organisations. Moreover, to address a particular limitation, it is important for further research to consider using explorative methods to discover possible themes pertaining to value creation in NPOs. Although there is evidence of entrepreneurship in NPOs, it is questionable whether the market economy is a suitable system for NPOs to operate in. However philosophical, research that explores areas beyond the boundaries of the marketeconomy discipline may help to motivate alternative systems or mechanisms under which NPOs can thrive. Some prospective research questions to be addressed may include the following: "Do NPOs really operate in the market? How suitable is the market discipline for NPOs? What alternatives to the market discipline are there for NPOs?"

\section{References}

Abdul-Rashid, Z., Sambasivan, M. \& Johari, J. (2003). The influence of corporate culture and organisational commitment on performance. Journal of management development, 22(8), 708-728.

Albrecht, W. S., Stice, E. K. \& Stice, J. D. (2011). Financial Accounting: Concepts and applications. 11th ed. Mason, Ohio: South-Western, Cengage Learning.

Amezcua, A. S., Grimes, M. G., Bradley, S. W. \& Wiklund, J. (2013). Organizational sponsorship and founding environments: A contingency view on the survival of business-incubated firms, 1994-2007. Academy of Management Journal, 56(6), 1628-1654.

Argote, L. \& Miron-Spektor, E. (2011). Organizational learning: From experience to knowledge. Organization science, 22(5), 1123-1137.

Austin, J., Stevenson, H. \& Wei-Skillern, J. (2006). Social and commercial entrepreneurship: same, different, or both? Entrepreneurship theory and practice, 30(1), 1-22.

Bargraim, J., Potgieter, T., Schultz, H., Viede, C. \& Werner, A. (2003). Organisational Behaviour: A Contemporary South African Perspective. Pretoria: Van Schaik. 
Balser, D. \& McClusky, J. (2005). Managing stakeholder relationships and nonprofit organization effectiveness. Non profit Management and Leadership, 15(3), 295-315.

Chalmers, D. M. \& Balan-Vnuk, E. (2012). Innovating not-for-profit social ventures: Exploring the micro foundations of internal and external absorptive capacity routines. International Small Business Journal, 0266242612465630.

Chawarika, A. (2016). Assessment of the Critical Constraints to Wheat Production in Zimbabwe. Business and Social Sciences Journal, 1(1) 34-50.

Chimucheka, T. (2015). The Contribution of Entrepreneurship Education in Improving Entrepreneurial Skills and Knowledge of SMME Owners and Managers. Journal of Economics, 6(2), 149-155.

Chinomona, R., Lin, J. Y. C., Wang, M. C. H. \& Cheng, J. M. S. (2010). Soft power and desirable relationship outcomes: the case of Zimbabwean distribution channels. Journal of African Business, 11(2), 182-200.

Chiva, R., Grandío, A. \& Alegre, J. (2010). Adaptive and generative learning: Implications from complexity theories. International Journal of Management Reviews, 12(2), 114-129.

Cho, V. \& Huang, X. (2012). Professional commitment, organizational commitment, and the intention to leave for professional advancement: An empirical study on IT professionals. Information Technology \& People, 25(1), 31-54.

Collins, H. (2010). Creative research: the theory and practice of research for the creative industries. Ava Publishing.

Creswell, J. W. (2013). Research design: Qualitative, quantitative, and mixed methods approaches $4^{\text {th }}$ Edition London UK. Sage publications.

Crutchfield, L. R. \& Grant, H. M. (2012). Forces for good: The six practices of high-impact nonprofits. USA. San Francisco. John Wiley \& Sons.

Dawes, J. G. (2008). Do data characteristics change according to the number of scale points used? An experiment using 5 point, 7 point and 10 point scales. International journal of market research, 51(1), 61-77

Department of Social Development. (2014). Non Profit Organisation. [Online] Available at: http://www.dsd.gov.za/npo/ [Accessed 28 June 2014]

Draper, J., Clark, L. \& Rogers, J. (2016). Managers' role in maximising investment in continuing professional education: Jan Draper and colleagues look at ways to create positive cultures that make the most of learning in practice. Nursing Management, 22(9), 30-36.

Drejer, A. (2000). Organisational learning and competence development. The learning organization, 7(4), 206220.

Drucker, P. F. (1998). The discipline of innovation. Harvard business review, 76(6), 149-157.

Fagarasanu, M. \& Kumar, S. (2002). Measurement instruments and data collection: a consideration of constructs and biases in ergonomics research. International Journal of Industrial Ergonomics, 30(6), 355-369.

Fairlie, R. W. \& Holleran, W. (2012). Entrepreneurship training, risk aversion and other personality traits: Evidence from a random experiment. Journal of Economic Psychology, 33(2), 366-378.

Fu, F. Q., Bolander, W. \& Jones, E. (2009). Managing the drivers of organizational commitment and salesperson effort: An application of Meyer and Allen's three-component model. Journal of Marketing Theory and Practice, 17(4), 335-350

Galpin, J. S. (2013). Statistical research design and analysis. [Lecture notes]. Johannesburg, South Africa: University of the Witwatersrand, School of Statistics and Actuarial Science

Garcia-Morales, V. J., Llorens-Montes, F. J. \& Verdú-Jover, A. J. (2006). Antecedents and consequences of organizational innovation and organizational learning in entrepreneurship. Industrial Management \& Data Systems, 106(1), 21-42

Grobman, G. M. (2008). The nonprofit handbook: Everything you need to know to start and run your nonprofit organization.

Harris, M. (2012).Nonprofits and business toward a subfield of nonprofit studies. Nonprofit and voluntary sector quarterly, 41(5), 892-902.

Hooper, D., Coughlan, J. \& Mullen, M. (2008). Structural equation modelling: Guidelines for determining model fit. Articles, 2.

Hult, G. T. M. (2011). Market-focused sustainability: market orientation plus! Journal of the Academy of Marketing Science, 39(1), 1-6. 
Kantur, D. (2016). Strategic entrepreneurship: mediating the entrepreneurial orientation-performance link. Management Decision, 54(1).

Kao, R. W., Kao, K. R. \& Kao, R. R. (2005). An entrepreneurial approach to stewardship accountability: Corporate residual and global poverty. USA. Massettussetts: World Scientific Publishing.

King Committee on Corporate Governance. (2009). King Report on Governance for South Africa. Institute of Directors, Southern Africa.

Kong, E. (2007). The strategic importance of intellectual capital in the non-profit sector. Journal of Intellectual capital, 8(4), 721-731.

Kotler, P. \& Keller, K. (2012). Marketing management. Global ed. Harlow: Pearson Education

Kumar, V., Jones, E., Venkatesan, R. \& Leone, R. P. (2011). Is market orientation a source of sustainable competitive advantage or simply the cost of competing? Journal of marketing, 75(1), 16-30.

Matei, P. N., Bolcas, C. B., Badea, F. \& Carstea, C. (2010). Risk management: Key process in the current financial context. In Global Conference of Business and Financial Proceedings, 5(2), 47-51.

Maziriri, E. T. \& Chinomona, E. (2016). Modelling the Influence of Relationship Marketing, Green Marketing and Innovative Marketing on the Business Performance of Small, Medium and Micro Enterprises (SMMES). Journal of Economics and Behavioral Studies, 8(3), 127-139.

Miller, D., Steier, L. \& Breton-Miller, L. (2016). What Can Scholars of Entrepreneurship Learn From Sound Family Businesses? Entrepreneurship Theory and Practice, 40(3), 445-455.

Naidoo, V. (2010). Firm survival through a crisis: The influence of market orientation, marketing innovation and business strategy. Industrial marketing management, 39(8), 1311-1320.

Rivera-Santos, M., Holt, D., Littlewood, D. \& Kolk, A. (2015). Social entrepreneurship in sub-Saharan Africa. The Academy of Management Perspectives, 29(1), 72-91.

Schuster, T. \& Holtbrügge, D. (2014). Resource dependency, innovative strategies, and firm performance in BOP markets. Journal of Product Innovation Management, 31(S1), 43-59.

Sessa, V. I., London, M., Pingor, C., Gullu, B. \& Patel, J. (2011). Adaptive, generative, and transformative learning in project teams. Team Performance Management: An International Journal, 17(3/4), 146167.

Sullivan Mort, G., Weerawardena, J. \& Carnegie, K. (2003). Social entrepreneurship: Towards conceptualisation. International journal of nonprofit and voluntary sector marketing, 8(1), 76-88.

Weerawardena, J. \& Sullivan-Mort, G. (2001). Learning, innovation and competitive advantage in not-forprofit aged care marketing: A conceptual model and research propositions. Journal of Nonprofit\& Public Sector Marketing, 9(3), 53-73.

Wood, V. R., Bhuian, S. \& Kiecker, P. (2000). Market orientation and organizational performance in not-forprofit hospitals. Journal of Business Research, 48(3), 213-226.

Ullman, J. B. \& Bentler, P. M. (2003). Structural equation modelling. John Wiley \& Sons, Inc.

Van Vuuren, L. J. \& Crous, F. (2005). Utilising appreciative inquiry (AI) in creating a shared meaning of ethics in organisations. Journal of Business Ethics, 57(4), 399-412

Venter, M., Chuchu, T. \& Pattison, K. (2016). An empirical investigation into the effectiveness of consumer generated content on the purchase intention of sports apparel brands. Journal of Contemporary Management, 13, 27-54

Yujuico, E. (2008). Connecting the dots in social entrepreneurship through the capabilities approach. Socioeconomic review, 6(3), 493-513. 